\title{
Affective discrimination of stimuli that are not recognized: II. Effect of delay between study and test
}

\author{
JOHN G. SEAMON, NATHAN BRODY, and DAVID M. KAUFF \\ Wesleyan University, Middletown, Connecticut
}

\begin{abstract}
This study found that repeated exposure to briefly presented stimuli increased positive affect through familiarity without enhancing recognition of the stimuli. Following exposure, subjects selected previously shown target stimuli on the basis of affect in the absence of stimulus recognition. Interpreted in terms of the manner in which information can be accessed in long-term storage, this study extends earlier research by showing that the ability to select target stimuli by affect can occur undiminished over a delay of 1 week between study and test. Repeated processing during study can produce a form of perceptual learning, called perceptual fluency, that can serve as the basis for stimulus discrimination in the absence of recognition at the time of test. The present results of familiar, but unrecognized, stimuli are analogous to the memory phenomenon of déjà vu.
\end{abstract}

Kunst-Wilson and Zajonc (1980) presented subjects with a series of 10 irregular polygons that were shown five times each at a brief exposure duration. In subsequent forced-choice judgments of affect (Which stimulus do you like?) or recognition (Which stimulus did you see before?), subjects selected previously seen stimuli at a better-than-chance level only for affect judgments. This increase in positive affect is called the exposure effect, and it results from repeated presentations of unfamiliar stimuli. To Zajonc (1980), affective preference for stimuli that cannot be remembered constituted evidence for the separation of "affective and cognitive" processes.

Seamon, Brody, and Kauff (1983) replicated and extended the Kunst-Wilson and Zajonc (1980) finding that repeated exposure to briefly presented stimuli increased positive affect without enhancing stimulus recognition. But, rather than viewing the difference between affect and recognition judgments as evidence for separate channels of processing, Seamon et al attributed the difference in judgments to different ways in which stimulus representations might be accessed in memory. Target selection by affect in the absence of recognition is an unusual phenomenon, but it can be explained by existing models of recognition memory (e.g., Atkinson \& Juola, 1973; Mandler, 1980; Mandler, Pearlstone, \& Koopmans, 1969).

Assuming that stimuli may be recognized on the basis of either familiarity or a memory search, when subjects are asked to discriminate stimuli on the basis of affect, they may do so indirectly through familiarity. Subjects like previously seen stimuli because of their familiarity,

This research was supported by a Wesleyan University Grant in Support of Scholarship. Requests for reprints should be sent to John Seamon, Department of Psychology, Wesleyan University, Middletown, Connecticut 06457. and this serves as a basis for selecting target stimuli. Familiarity, however, is not in the stimulus, but in the perceptual act of processing the stimulus (Neisser, 1967). Repeated stimulus exposure produces a form of perceptual learning called perceptual fluency (Jacoby \& Dallas, 1981), which can serve as a basis for stimulus discrimination in the absence of recognition. Subjects like target stimuli, more than they do distractor stimuli, because they are familiar with processing them. When subjects are asked to discriminate stimuli on the basis of recognition, they engage in a memory search in which they attempt to retrieve a prior context for each given stimulus. Retrieving information about either perceptual fluency or a prior context, subjects can like previously seen stimuli without recognizing them or can recognize previously seen stimuli without liking them. Either outcome is possible.

The distinction between affect and recognition judgments in terms of different retrieval processes suggests a test of the independence of both judgments. Kolers $(1975,1976)$ found that memory for the pattern recognition operations involved in reading unusual script remained strong for at least a year, even though memory for the specific occasions on which the material was read was not well retained. Said Kolers, "Knowledge can be expressed as skilled performance without a corresponding recognition in conscious judgment" (Kolers, 1976, p. 563). Applied to the present research, subjects should select previously seen stimuli at a better-than-chance level even with a delay between study and test if affect judgments are based on perceptual fluency, a skill acquired through repeated processing. Target selection on the basis of recognition, however, should approximate chance frequency, since successfully retrieving a prior context should become increasingly difficult with increasing delay between study and test. The pre- 
dicted differential effect of test delay on affect and recognition judgments, then, served as the basis for this experiment.

\section{METHOD}

\section{Subjects}

The subjects were 64 18-22-year-old Wesleyan University students, who served as paid volunteers. All of the subjects were right-handed, and none had participated in any prior study of affect or recognition.

\section{Materials and Apparatus}

The study and test stimuli and experimental apparatus were the same as those used previously by Seamon et al. (1983).

\section{Procedure}

The procedure involved a replication of Experiment 4 (pattern mask condition) of Seamon et al. (1983). Briefly, the subjects were shown 10 geometric shapes five times each in five random orders of 10 . During study, half of the stimuli were presented in the left visual field ( $1 \mathrm{deg}$ to the left of fixation) and half were presented in the right visual field ( $1 \mathrm{deg}$ to the right of fixation). After viewing each of the 50 study stimuli for $5 \mathrm{msec}$ and then a 10 -msec pattern mask, the subjects were presented with 10 test trials. Each trial, shown for $1 \mathrm{sec}$ at a self-paced rate, contained a previously shown target stimulus and a distractor stimulus of comparable complexity. The subjects were asked to select the stimulus they liked best (forced-choice affect judgment) or the stimulus they had seen before (forced-choice recognition judgment). After making one type of judgment for all 10 trials, the trials were repeated and the alternate judgment was used. Half of the subjects made the affect judgments before the recognition ones, and half made the recognition judgments before the affect ones. (See Seamon et al., 1983, for additional details.)

This experiment differed from its predecessor in one important respect. Instead of testing all subjects immediately after viewing the study stimuli, the time between study and test was experimentally manipulated. One group of 20 subjects was tested immediately after the study stimuli had been shown, a second group of 20 subjects was tested 1 day after having viewed the study stimuli, and a third group of 24 subjects was tested 1 week after having seen the study stimuli. The order of making affect and recognition judgments was counterbalanced in each group and equal across groups.

\section{RESULTS}

The design for this experiment was a mixed design with two between-subjects variables, judgment order and delay of test, and two within-subjects variables, judgment type and visual field of exposure during study. The basic findings are summarized in Table 1 , which presents target selection as a function of judgment type and delay of test. Due to an absence of visual-field differences during study, the data were collapsed over this variable for

Table 1

Mean Percent Target Selection by

Judgment Type and Test Delay

\begin{tabular}{cccc}
\hline & \multicolumn{3}{c}{ Test Delay } \\
\cline { 2 - 4 } Judgment Type & Immediate & 1 Day & 1 Week \\
\hline Affect & 60.5 & 60.0 & 65.0 \\
Recognition & 55.5 & 52.5 & 50.8 \\
\hline
\end{tabular}

Note-Chance performance equals $50 \%$. all subjects. Table 1 shows that affect judgments yielded better target selection than recognition judgments, and affect judgments of target stimuli were not affected by a delay between study and test. The results of a mixeddesign analysis of variance confirmed these observations: Significant alone was the main effect of judgment type $[F(1,60)=15.36, p<.001]$. For each of the means shown in Table $1, t$ tests showed greater-than-chance performance for each group when affect judgments were made (all ps $<.01$ ), but not when recognition judgments were made (all ps $>.05$ ). Finally, the slight increase in performance for affect judgments after a 1-week delay was not significantly greater than that for the immediate or 1-day delay conditions (both ps $>.05$ ). Accordingly, there is no evidence for hypermnesia over time, a phenomenon that has been observed in repeated recalls of picture stimuli (Erdelyi \& Becker, 1974; Yarmey, 1976).

Under conditions of immediate testing, Seamon et al. (1983) found comparable scores for affect $(63 \%)$ and recognition (58\%) judgments in their fourth experiment. The present data replicate the affect-recognition distinction and show that affect judgments are unchanged by delays of up to 1 week. Not consistent across experiments was the failure to find visual-field differences for the study stimuli. Reminiscent of the inconsistent effects of verbal shadowing during study found previously (Seamon et al., 1983), the visual field differences found earlier were not observed in this experiment. Overall, the subjects in this experiment were unaffected by the visual field of exposure of the study stimuli for either affect or recognition judgments. ${ }^{1}$

\section{DISCUSSION}

The present study confirms the results of Kunst-Wilson and Zajonc (1980) and Seamon et al. (1983): Subjects can select target stimuli on the basis of affect in the absence of stimulus recognition. This study extends the earlier research by showing that the ability to select target stimuli by affect can occur undiminished over a delay of 1 week between study and test. The length of this delay indicates that target selection by affect is based on processes or codes that are represented in long-term storage at the time of the test. Consistent with the view that repeated stimulus exposure produces processing familiarity (Kolers, 1975, 1976), affect judgments were resistant to the effects of time or events that intervened between study and test.

If target selection by affect is viewed as an example of longterm perceptual fluency, it is a skill that is acquired very quickly; few exposures of briefly presented stimuli are necessary to render them familiar. In one sense, at least, target selection by affect is analogous to the déjà vu phenomenon in everyday memory. People or places that seem familiar, but have not been seen before, may be similar to previously encoded stimuli. The experience of déjà vu (literally "previously seen") is an expression of the familiarity of a similar stimulus without the retrieval of that earlier event or its context into conscious awareness (Glass, Holyoak, \& Santa, 1979; Hunter, 1957). In déjà vu, stimuli are recognized as familiar without recognition of the basis of their familiarity. Essentially, the same outcome was observed in this study: People liked familiar stimuli without recognizing the basis for their familiarity. In this respect, the finding of target selection by affect in the absence of recognition is similar to the well-known, but poorly understood, phenomenon of déjà vu. 


\section{REFERENCES}

Atrinson, R. C., \& Juola, J. F. Factors influencing speed and accuracy of word recognition. In S. Kornblum (Ed.), Attention and performance IV. New York: Academic Press, 1973.

ERdelyi, M. H., \& Becker, J. Incremental memory for pictures: Hypermnesia for pictures but not for words in multiple recall trials. Cognitive Psychology, 1974, 6, 159-171.

Glass, A. L., Holyoak, K. J., \& Santa, J. L. Cognition. Reading, Mass: Addison-Wesley, 1979.

Hunte R, I. M. L. Memory. Baltimore: Penguin Books, 1957.

JACOBY, L. L., \& Dallas, M. On the relationship between autobiographical memory and perceptual learning. Journal of Experimental Psychology: General, 1981, 110, 306-340.

Kolers, P. Memorial consequences of automatized encoding. Journal of Experimental Psychology: Human Learning and Memory, 1975, 1, 689-701.

Kolers, P. Reading a year later. Journal of Experimental Psychology: Human Learning and Memory, 1976, 2, 554-565.

Kunst-Wilson, W. R., \& Zajonc, R. B. Affective discrimination of stimuli that cannot be recognized. Science, 1980, 207, 557-558.

Mandler, G. Recognizing: The judgment of previous occurrence. Psychological Review, 1980, 87, 252-271.

Mandler, G., Pearlstone, Z., \& Koopmans, H. S. Effects of organization and semantic similarity on recall and recognition. Journal of Verbal Learning and Verbal Behavior, 8, 410-423.

Neisser, U. Cognitive Psychology. New York: Appleton-CenturyCrofts, 1967.
Seamon, J. G., Brody, N., \& Kauff, D. M. Affective discrimination of stimuli that are not recognized: Effects of shadowing, masking, and cerebral laterality. Journal of Experimental Psychology: Learning, Memory, and Cognition, 1983, 9, 544-555.

YARMEY, A. D. Hypermnesia for pictures but not for concrete or abstract words. Bulletin of the Psychonomic Society, 1976, 8, 115-117.

ZAJONC, R. B. Feeling and thinking: Preferences need no inferences. American Psychologist, 1980, 35, 151-175.

\section{NOTE}

1. It was discovered that the study stimuli were not always presented $1 \mathrm{deg}$ to the left or right of fixation. Owing to slight random movements of the mirror in the two-channel tachistoscope, the stimuli were not presented in a spatially consistent manner across visual fields. Because of a failure to adjust the mirror before each experimental session, the effect of the visual field variable would be diminished. These slight changes in spatial positioning of the study stimuli, however, could in no way alter the performance difference between affect and recognition judgments. Regardless of the variations in stimulus position during study, all subjects made both types of judgments on those stimuli during test.

(Manuscript received for publication April 11, 1983.) 